\title{
Antiepileptic Drugs, Sexual Functions and Serum Hormonal Profile in Males with Epilepsy
}

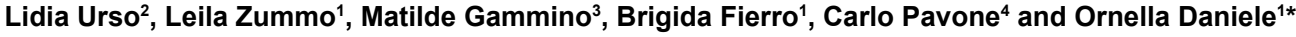 \\ ${ }^{1}$ Department of Experimental Biomedicine and Clinic Neuroscience, University of Palermo, Italy \\ ${ }^{2}$ Civic Hospital S. Antonio Abate - Trapani \\ ${ }^{3}$ Civic Hospital ARNAS - Palermo \\ ${ }^{4}$ Department of Surgical Oncological and Stomatologic Disciplines, University of Palermo, Italy
}

\begin{abstract}
Sexual dysfunctions are a common problem in epileptic men. Etiology is multifactorial involving both epilepsy and antiepileptic drugs. Purpose of this study was to evaluate incidence of sexual dysfunctions in epileptic men, assessing epilepsy, antiepileptic drugs, serum hormonal profile, psychiatric disorders.
\end{abstract}

Keywords: Sexual dysfunctions; Sex hormones; Epilepsy

\section{Introduction}

Sexual dysfunctions significantly reduce the quality of life in general population with a prevalence estimated between 20 and $22 \%$. Most frequent reported sexual dysfunctions are: erectile dysfunction, reduced libido, orgasmic and ejaculation dysfunctions. Aetiology of such disturbances is often related to various co-morbidity such as cardiovascular disease, hyperglycaemia, hypertension and hypercholesterolemia. As far as patients with neurologic disease, epileptic patients are likely to have a greater risk for sexual dysfunctions if compared with general population [1].

Epilepsy is a chronic neurological condition characterised by recurrent epileptic seizures. They happen because of sudden, abnormal electrical activity in the brain, there are many types of seizures and some have mild symptoms. Seizures are divided into two main groups: focal seizures that happen in just one part of the brain, and generalized that are a result of abnormal activity on both sides of the brain. Epilepsy has many possible causes, including illness, brain injury, and abnormal brain development, but sometimes the cause is unknown [2,3].

The epilepsy syndrome and localization influence the presentation of sexual dysfunction. Studies report higher percentages of sexual dysfunction in persons with temporal lobe epilepsy compared to primary generalized epilepsy [4,5]. Not only epilepsy but also Antiepileptic Drugs (AEDs) affect hormones and neuroendocrine systems. So aetiology of such dysfunctions in patients with epilepsy is multifactorial including: disease by itself, epileptic seizures, drug therapy, life style and psychological problems in addition to the physiologic effects of epileptic discharges in brain regions mediating sexual behaviour $[6,7]$.

In patients with epilepsy the prevalence of sexual dysfunctions varies between 38 and $71 \%$; this variability is strictly related to the correct definition of "sexual dysfunction". So, some authors indicate generic sexual dysfunctions with the term "hyposexuality", but more recently, the growing interest in this topic allowed us to identify more exactly the type of sexual dysfunctions: reduced libido, orgasmic and erectile dysfunctions, satisfaction from sexual intercourse and sexual life of the patient [8-10]. The epilepsy itself, type of seizures and their frequency are influencing and influence hypothalamic and pituitary structures and, consequently, the regular hormonal release, inducing an impairment of the correct sexual function [11]. Studies in literature show that temporal lobectomy can reverse hormonal changes associated with temporal lobe epilepsy if complete seizure control is achieved $[12,13]$.
Also antiepileptic therapy, and mainly enzyme-inducing drugs, impaired not only hormonal release, but also the protein- binding sexual hormones, modifying in turn share of active hormone in blood circulation. Furthermore, in people with epilepsy, anxiety, depression and social stigmate are to be kept in mind as they strengthen the illness limiting the quality of life of these patients [14-17].

The aim of the present prospective study is to evaluate the incidence of sexual dysfunctions in males with epilepsy, the type of epilepsy, the frequency of seizures, the type of Antiepileptic Drugs (AEDs) in mono or poly-therapy, the serum hormonal profile and the presence of psychiatric co-morbidity.

\section{Patients and Methods}

We enrolled 61 patients, consecutively, focusing on type of epilepsy, frequency of seizures, AEDs, hormonal profile and presence of mood disorders. We excluded all patients with severe neurologic and psychiatric impairment and patient who were not able to fill questionnaires.

Mean age was 31.2 years (range $18-50$ years); 31 patients (50.8\%) had an idiopathic generalised epilepsy and 30 (49.2\%) a focal epilepsy; among them latter $18(60 \%)$ had probably symptomatic type and 12 (40\%) symptomatic type (Table 1 ).

Patients with focal epilepsy included $6(20 \%)$ with frontal lobe epilepsy, 16 (53.3\%) with temporal lobe epilepsy, 3 (10\%) with occipital lobe epilepsy and $5(16.7 \%)$ with multifocal epilepsy. The seizures were frequent monthly or daily in 29 patients $(47.5 \%)$.

As far as type of therapy is concerned 48 patients (78.7\%) were on monotherapy and the remaining $13(21.3 \%)$ on polytherapy. Valproate (VPA) was the most used drug (25 out of 61 patients; $41 \%$ ), alone or associated with Carbamazepine (CBZ) (14), Levetiracetam (LEV) and

*Corresponding author: Ornella Daniele, Department of experimental biomedicine and clinic neuroscience, University of Palermo, Via G. La Loggia 190129 Palermo Italy, Tel: 00390916555171 - 0916555107; Fax: 0039 0916555172; E-mail: ornella.daniele@unipa.it

Received January 17, 2014; Accepted March 25, 2014; Published March 29 2014

Citation: Urso L, Zummo L, Gammino M, Fierro B, Pavone C, et al. (2014) Antiepileptic Drugs, Sexual Functions and Serum Hormonal Profile in Males with Epilepsy. Med Surg Urol 3: 130. doi:10.4172/2168-9857.1000130

Copyright: (c) 2014 Urso L, et al. This is an open-access article distributed under the terms of the Creative Commons Attribution License, which permits unrestricted use, distribution, and reproduction in any medium, provided the original author and source are credited. 


\begin{tabular}{|c|c|}
\hline Demographics & Cases $\mathbf{n = 6 1}$ (\%) \\
\hline Mean age & 31.2 \\
\hline Focal epilepsy & $30 / 61(49.2)$ \\
\hline Generalized epilepsy & $31 / 61(50.8)$ \\
\hline Idiopathic epilepsy & $31 / 61(50.8)$ \\
\hline Probably symptomatic epilepsy & $12 / 30(40)$ \\
\hline Symptomatic epilepsy & $18 / 30(60)$ \\
\hline Frontal lobe epilepsy & $6 / 30(20)$ \\
\hline Temporal lobe epilepsy & $16 / 30(53.3)$ \\
\hline Occipital lobe epilepsy & $3 / 30(10)$ \\
\hline Multifocal epilepsy & $5 / 30(16.7)$ \\
\hline
\end{tabular}

Table 1: Demographics.

Lamotrigine (LTG)(9), Phenobarbital (PB) (8), Topiramate (TPM) (7) and oxcarbazepine (OXC) (6) (Table 2).

All patients enrolled were subjected to measurement of blood total testosterone levels, free testosterone, Dehydroepiandrosterone Sulphate (DHEAS) and delta-4-androstenedione.

Sexual functions were evaluated by means of structural questionnaire "International Inventory of Erectile Function" IIEF which evaluates erectile function (IIEF I), orgasmic function (IIEF II), sexual drive (IIEF III), satisfaction intercourse (IIEF IV) and whole satisfaction of sexual life (IIEF V).

To evaluate mood disorders all patients performed Hamilton Rating Scale for Depression (HRSD). Statistical analysis was performed on the basis of Chi-square test to evaluate categorical variables and Student's $t$ test to analyze continuous variables. Statistical significance level was fixed as $\mathrm{p}<0.05$.

The protocol and procedures employed were reviewed and approved by the Local Research Ethics Committee for recruitment patients and the control group.

\section{Results}

Out of 61 enrolled patients, $22(36.7 \%)$ showed sexual dysfunctions: erectile dysfunctions in $14(23 \%)$, orgasmic dysfunctions in $(11.5 \%)$ and sexual drive dysfunctions in 12 (19.7\%) (Table 3).

Patients with sexual dysfunctions included 14 on monotherapy and 8 on polytherapy (VPA in 8, 6 PB, 5 TPM, 3 LEV, 3 LTG, 3 OXC).

Out of 61 patients, 36 were subjected to blood measurement of sexual hormones and 21 (58.3\%) showed hormonal modifications: blood increased total testosterone was found in 6 patients $(16.7 \%)$, reduced free testosterone was found in $12(33.3 \%)$ and increased free testosterone in 7 (19.4\%). Reduced levels of DHEAS were found in 9 patients (25\%) and increased levels of DHEAS associated with reduced levels of Delta androstenedione in only one (Table 4).

In our study, as reported in the literature (Parazzini et al 2000), there is an increased prevalence in sexual dysfunctions (SD), and actually, mean age of epileptics with SD (39.36) is significantly greater if compared with that of patients without SD (29.54) with $\mathrm{t}=4.544$ and $\mathrm{p}<0.0001$ (Table 5).

There is not any significant association between focal/generalized epilepsy and sexual changes $\left(\chi^{2}=0.132, p=0.7167\right)$ nor between focal frontal $\left(\chi^{2}=0.091, p=0.7635\right)$, temporal $\left(\chi^{2}=0.196, p=0.6583\right)$, occipital $\left(\chi^{2}=0.515, \mathrm{p}=0.4730\right)$, multifocal epilepsy $\left(\chi^{2}=1.297, \mathrm{p}=0.2547\right)$ and sexual dysfunctions. These latter are not associated with increased frequency of seizures $\left(\chi^{2}=0.309, p=0.5783\right)$ (Table 6).
Analyzing data concerning the relationship between sexual dysfunction and AEDs, we did not find any significant association with mono or polytherapy (VPA, LEV, TPM, LTG, CBZ, OXC) $\left(\chi^{2}=3.351\right.$, $\mathrm{p}=0.0672)$; except for a weak significance between $\mathrm{PB}$ and sexual dysfunctions $\left(\chi^{2}=4.266, \mathrm{p}=0.0389\right)$ (Table 7).

Our data do not indicate any association between hormonal changes and focal/generalized epilepsy as well as various types of focal epilepsy (frontal, temporal, occipital, multifocal) (Table 8).

A positive relationship was found between hormonal changes and

\begin{tabular}{|c|c|}
\hline On monotherapy & $48 / 61(78.7)$ \\
\hline On polytherapy & $13 / 61(21.3)$ \\
\hline VPA & $25 / 61(41.0)$ \\
\hline LEV & $9 / 61(14.8)$ \\
\hline TPM & $7 / 61(11.5)$ \\
\hline LTG & $9 / 61(14.8)$ \\
\hline CBZ & $14 / 61(23.0)$ \\
\hline OXC & $6 / 61(9.8)$ \\
\hline PB & $8 / 61(13.1)$ \\
\hline
\end{tabular}

Table 2: Drug Therapy.

\begin{tabular}{|c|c|}
\hline & Cases $\mathbf{n = 6 1}(\mathbf{\%})$ \\
\hline Sexual dysfunctions & $22 / 61(36.7)$ \\
\hline Erectile dysfunctions & $14 / 61(23.0)$ \\
\hline Orgasmic dysfunctions & $7 / 61(11.5)$ \\
\hline Sexual drive trouble & $12 / 61(19.7)$ \\
\hline
\end{tabular}

Table 3: Types of sexual dysfunctions.

\begin{tabular}{|c|c|}
\hline Hormonal impairment & $21 / 36(58.3)$ \\
\hline Total testosterone increased & $6 / 36(16.7)$ \\
\hline Free testosterone reduced & $12 / 36(33.3)$ \\
\hline Free testosterone increased & $7 / 36(19.4)$ \\
\hline Reduced DHEAS & $9 / 36(25)$ \\
\hline Increased DHEAS & $1 / 36(2.7)$ \\
\hline Reduced Delta androstenedione & $1 / 36(2.7)$ \\
\hline
\end{tabular}

Table 4: Type of hormonal impairment.

\begin{tabular}{|l|c|c|c|c|}
\hline & $\begin{array}{c}\text { Pts with sexual } \\
\text { dysfunctions }\end{array}$ & $\begin{array}{c}\text { Pts with no } \\
\text { dysfunctions }\end{array}$ & $\mathbf{t}$ (Student's Test) & p \\
\hline Mean age & 39.36 & 29.54 & 4.544 & 0.0001 \\
\hline
\end{tabular}

Table 5: Mean age of epileptics with sexual changes.

\begin{tabular}{|c|c|c|}
\hline & $\mathbf{X}^{2}$ & $\mathbf{p}$ \\
\hline Sexual dysfunctions and types (focal or generalized) epilepsy & 0.132 & 0.7167 \\
\hline Sexual dysfunctions and frontal lobe epilepsy & 0.091 & 0.7635 \\
\hline Sexual dysfunctions and temporal lobe epilepsy & 0.196 & 0.6583 \\
\hline Sexual dysfunctions and occipital lobe epilepsy & 0.515 & 0.4730 \\
\hline Sexual dysfunctions and multifocal epilepsy & 1.297 & 0.2547 \\
\hline Sexual dysfunctions and increased frequency of seizures & 0.309 & 0.5783 \\
\hline
\end{tabular}

Table 6: Sexual dysfunctions and epilepsy.

\begin{tabular}{|c|c|c|}
\hline & $\mathbf{X}^{\mathbf{2}}$ & $\mathbf{p}$ \\
\hline Sexual dysfunctions and mono/polytherapy & 3.351 & 0.0672 \\
\hline Sexual dysfunctions and VPA & 0.078 & 0.7795 \\
\hline Sexual dysfunctions and LEV & 0.036 & 0.8485 \\
\hline Sexual dysfunctions and TPM & 2.731 & 0.0984 \\
\hline Sexual dysfunctions and LTG & 0.036 & 0.8485 \\
\hline Sexual dysfunctions and CBZ & 2.613 & 0.1060 \\
\hline Sexual dysfunctions and OXC & 0.091 & 0.7635 \\
\hline Sexual dysfunctions and PB & 4.266 & 0.0389 \\
\hline
\end{tabular}

Table 7: Sexual dysfunctions and AEDs. 


\begin{tabular}{|c|c|c|}
\hline & $\mathbf{X}^{2}$ & $\mathbf{p}$ \\
\hline Hormonal changes and types (focal or generalized) epilepsy & 0.214 & 0.6439 \\
\hline Hormonal changes and frontal lobe epilepsy & 0.842 & 0.3590 \\
\hline Hormonal changes and temporal lobe epilepsy & 0.127 & 0.7219 \\
\hline Hormonal changes and occipital lobe epilepsy & 0.968 & 0.3252 \\
\hline Hormonal changes and multifocal epilepsy & 0.029 & 0.8639 \\
\hline
\end{tabular}

Table 8: Hormonal changes and epilepsy.

the assumption of CBZ but not of other AEDs (VPA, LEV, TPM, LTG, OXC, $\mathrm{PB})\left(\chi^{2}=5.581, \mathrm{p}=0.0182\right)($ Table 9$)$.

We found, also, an association between hormonal changes and sexual dysfunctions in epileptic patients $\left(\chi^{2}=10.414, \mathrm{p}=0.0013\right)$, mainly with erectile dysfunction $\left(\chi^{2}=7.659, p=0.0056\right)$ and changes of sexual drive $\left(\chi^{2}=4.261, \mathrm{p}=0.0390\right)$,but not with orgasmic dysfunction $\left(\chi^{2}=0.242, \mathrm{p}=0.6228\right)($ Table 10$)$

Depression and sexual dysfunction are significantly related $\left(\chi^{2}=9.883, p=0.0017\right)$ : mainly concerning sexual drive $\left(\chi^{2}=37.773\right.$, $\mathrm{p}<0.0001)$, and erectile dysfunction $\left(\chi^{2}=5.553, \mathrm{p}=0.0185\right)$, but not orgasmia dysfunction $\left(\chi^{2}=0.062, \mathrm{p}=0.8038\right)$ (Table 11).

\section{Discussion}

Sexual dysfunctions have been reported in literature in $38.7 \%$ of males with epilepsy.

Hyposexuality is the predominant syndrome which is characterized by the loss of sexual desire, reduced sexual activity, and sexual arousal $[18,19]$. On the other hand organic sexual problems are also frequently seen; for example orgasm disturbances, erectile dysfunction, premature ejaculation and fertility problems due to hypogonadism [20].

In our study we used "International Inventory of Erectile Function" IIEF, a standardized questionnaire, to evaluate different sexual dysfunctions, and we found a prevalence of SD in $36.7 \%$ of patients $[18,19]$. Mean age of epileptics with sexual dysfunctions $(31.2$ years) is significantly greater if compared with that of patients without sexual dysfunctions, as reported in literature [9]. In nineties Petra et al. pointed out these data, relating them to an increase in levels of Sexual Hormone Binding Globuline (SHBG) in older epileptics [21]. It was hypothesized that ictal discharges involving cortical regions, which mediate sexual behavior, could play a role in genesis of various sexual dysfunctions; in particular limbic region: amygdala, and the corticomedial nucleus (both improving hypothalamic gonadotropin releasing hormone - GnRH - release) [22,23]. It is also possible that epileptic discharges could induce an abnormal bioavailability of serum hormonal concentrations, mainly of testosterone through an influence on hypothalamus, pituitary gland and eventually gonads [24,25].This seems to be confirmed in the study of Bauer et al. when after surgical removal of epileptogenetic focus an increase in serum level of total and free testosterone has been found [26]. Actually several studies showed that particularly men with temporal lobe epilepsy are affected. Temporal Lobe Epilepsy (TLE) is involved assuming an altered secretion of $\mathrm{GnRH}$ from the hypothalamus connected to temporal lobe.

In our study we did not find any significant relationship between a particular type of focal or generalized epilepsy and sexual dysfunctions, nor analyzing seizure severity or seizure frequency as it has been described in literature [27]. It could be explain, first of all, considering our small sample.

The reasons for developing sexual dysfunction are multi-factorial. Some of the symptoms are caused by the epilepsy itself while others may be caused by the antiepileptic medication. Analyzing the relationship between AEDs and SD we did not find any significant associations with mono or polytherapy, and the presence of sexual dysfunctions, except for a weak significance between PB and SD. Even if we did not find a statistical significance, it is anyway interesting that we found SD in 8 of 13 patients (62\%) on polytherapy, while only 14 of $48(29 \%)$ monotherapy patients were affected. So we may speculate an association between chronic polytherapy and sexual dysfunctions in epileptic men.

As already known in the literature these data could be related to the activity of enzyme-inducing drugs on microsomial system which increase metabolism of sexual hormones, and production of proteins binding sexual hormones (SHBG) actually inducing a decrease of the amount of free, and biologically active, hormone. In a small sample of epileptics who assumed carbamazepine, Connel et al. found a decrease of total testosterone and an increase of SHBG comparing them to a group of controls [27]. Rattya confirmed these results in his study on 90 epileptics who assumed carbamazepine, oxcarbazepine and VPA; only patients who assumed $\mathrm{CBZ}$ and $\mathrm{OXC}$ showed hormonal variations related to sexual dysfunctions if compared to controls and those who assumed VPA $[17,28]$. However, there is sufficient evidence to suggest that particularly the strong enzyme-inducing antiepileptic drugs, which are metabolized in the liver, such as carbamazepine, phenytoin, phenobarbital or primidone, change the hormone balance of the male organism. These substances enhance the activity of the hepatic cytochrome-P450 enzyme system and increase the formation of sexual hormone binding globulin which, in return, reduces the free biologically active testosterone and increases the inactive bound form [29]. Because of sexual hormones are very important in supporting sexual drive and sexual function in man and in women it is thought contributing to the sexual dysfunction observed in patients with epilepsy who are on chronic treatments. In our study, due to the small number of patients in each AED group, it would be worth a comparison between SD and AEDS pooling enzyme-inducing versus non-inducing medications. But, because of some patients are on polytherapy, (including both enzyme-inducing and non-inducing AEDs), it couldn't be possible analyzing these data.

Instead we found a statistically significant association between

\begin{tabular}{|c|c|c|}
\hline & $\mathbf{X}^{\mathbf{2}}$ & $\mathbf{p}$ \\
\hline Hormonal changes and VPA & 1.150 & 0.2836 \\
\hline Hormonal changes and LEV & 0.166 & 0.6838 \\
\hline Hormonal changes and TPM & 0.242 & 0.6228 \\
\hline Hormonal changes and LTG & 0.823 & 0.3643 \\
\hline Hormonal changes and CBZ & 5.581 & 0.0182 \\
\hline Hormonal changes and OXC & 0.094 & 0.7598 \\
\hline Hormonal changes and PB & 2.222 & 0.1360 \\
\hline
\end{tabular}

Table 9: Hormonal changes and AEDs.

\begin{tabular}{|c|c|c|}
\hline & $\mathbf{X}^{\mathbf{2}}$ & $\mathbf{p}$ \\
\hline Hormonal changes and sexual dysfunctions & 10.414 & 0.0013 \\
\hline Hormonal changes and erectile dysfunctions & 7.659 & 0.0056 \\
\hline Hormonal changes and sexual drive & 4.261 & 0.0390 \\
\hline Hormonal changes and orgasmic dysfunctions & 0.242 & 0.6228 \\
\hline
\end{tabular}

Table 10: Hormonal changes and sexual dysfunctions.

\begin{tabular}{|c|c|c|}
\hline & $\mathbf{X}^{\mathbf{2}}$ & $\mathbf{p}$ \\
\hline Depression and sexual dysfunctions & 9.883 & 0.0017 \\
\hline Depression and erectile dysfunctions & 5.553 & 0.0185 \\
\hline Depression and sexual drive & 37.773 & 0.0001 \\
\hline Depression and orgasmic dysfunctions & 0.062 & 0.8038 \\
\hline
\end{tabular}

Table 11: Depression and sexual dysfunctions. 
the hormonal changes and $\mathrm{SD}\left(\chi^{2}=10.414, \mathrm{p}=0.0013\right)$. In particular an association between blood increased total testosterone, free testosterone and increased levels of DHEAS with erectile dysfunction $\left(\chi^{2}=7.659, \mathrm{p}=0.0056\right)$ and sexual drive $\left(\chi^{2}=4.261, \mathrm{p}=0.0390\right)$, but not with orgasmic dysfunction $\left(\chi^{2}=0.242, \mathrm{p}=0.6228\right)$.

We did not find any significant relationship between a particular type of focal or generalized epilepsy and hormonal changes. Also in our study the presence of hormonal changes does not seem to be associated with any type of AEDs, including the new ones (LEV, TPM, LTG, OXC), except for CBZ ( $\left.\chi^{2}=5.581, p=0.0182\right)$, as reported by Rättyä et al. [17] and Connell et al. [27].

Anyway in epileptic men various mechanisms play a role in sexual dysfunction. Psychosocial factors that can impair sexuality, such as limitation of social contacts and poor self-esteem, affect a relatively large proportion of the population with epilepsy.

In our study we, also, hypothesized that depression could play a role in epileptic males. By mean of HRSD we found a statistically relationship between depression and sexual dysfunctions, mainly concerning change in sexual drive, even though it is not so easy to rule out the possibility that depression is the consequence of sexual dysfunctions.

On the other hand Duncan (2005) also evaluated the association between sexual dysfunctions and hormonal variations indicating a marked decrease in serum values of serotonine as effect of the disease on limbic system within sexual dysfunction. Until now studies relating troubles of mood and sexual dysfunctions are very few, as well as drug therapy

The initial important factor is acknowledgment of sexual dysfunction as a common problem associated with epilepsy. Patients are often too embarrassed to discuss these problems or may even lack subjective appreciation of their presence and extent. Physicians, too, are often uncomfortable about addressing them or may fail to recognize their frequency and importance. For the optimal care of patients with epilepsy, these barriers must be confronted and surmounted.

\section{Conclusion}

The results of the present study showed:

- sexual dysfunction are present in $36.7 \%$ of enrolled males with epilepsy

- mean age of males with epilepsy is significantly greater than of those without sexual dysfunctions

- there is not any significant association between sexual dysfunctions (focal or generalized epilepsy), as well as with any type of focal (frontal, temporal, occipital, multifocal) epilepsy

- there is any association between sexual dysfunctions various AEDs in the treatment, except for CBZ

- there is not any association between sexual dysfunctions and frequency of seizures

- hormonal changes are associated with sexual dysfunction in males with epilepsy treated with AEDs mainly the erectile dysfunction and change in sexual drive but not with the orgasmic dysfunction

- there is not any association between hormonal changes and type of AEDs, except for CBZ

- depression is associated with sexual dysfunctions, mainly with change of sexual drive and the erectile dysfunction but not orgasmic dysfunction.

\section{References}

1. Hellmis E (2008) Sexual problems in males with epilepsy--an interdisciplinary challenge! Seizure 17: 136-140.

2. (1989) Proposal for revised classification of epilepsies and epileptic syndromes Commission on Classification and Terminology of the International League Against Epilepsy. Epilepsia 30: 389-399.

3. Engel J Jr; International League Against Epilepsy (ILAE) (2001) A proposed diagnostic scheme for people with epileptic seizures and with epilepsy: report of the ILAE Task Force on Classification and Terminology. Epilepsia 42: 796803

4. Morrell MJ, Flynn KL, Doñe S, Flaster E, Kalayjian L, et al. (2005) Sexua dysfunction, sex steroid hormone abnormalities, and depression in women with epilepsy treated with antiepileptic drugs. Epilepsy Behav 6: 360-365.

5. Harden CL (2005) Sexuality in women with epilepsy. Epilepsy Behav 7 Supp 2: S2-6.

6. Toone BK, Wheeler M, Nanjee M, Fenwick P, Grant R (1983) Sex hormones sexual activity and plasma anticonvulsant levels in male epileptics. J Neurol Neurosurg Psychiatry 46: 824-826.

7. Herzog AG (1989) A hypothesis to integrate partial seizures of temporal lobe origin and reproductive endocrine disorders. Epilepsy Res 3: 151-159.

8. Pritchard PB (1980) Hyposexuality: a complication of complex partial epilepsy Trans Am Neurol Assoc 105: 193-195.

9. Parazzini F, Menchini Fabris F, Bortolotti A, Calabrò A, Chatenoud L, et al. (2000) Frequency and determinants of erectile dysfunction in Italy. Eur Urol 37: $43-49$.

10. Nicolosi A, Moreira ED Jr, Shirai M, Bin Mohd Tambi MI, Glasser DB (2003) Epidemiology of erectile dysfunction in four countries: cross-national study of the prevalence and correlates of erectile dysfunction. Urology 61: 201-206.

11. Murialdo G, Galimberti CA, Fonzi S, Manni R, Costelli P, et al. (1995) Sex hormones and pituitary function in male epileptic patients with altered or normal sexuality. Epilepsia 36: 360-365.

12. Taylor DC (1969) Sexual behavior and temporal lobe epilepsy. Arch Neuro 21: $510-516$

13. Blumer D, Walker AE (1967) Sexual behavior in temporal lobe epilepsy. A study of the effects of temporal lobectomy on sexual behavior. Arch Neurol 16: 37-43.

14. Herzog AG, Drislane FW, Schomer DL, Pennell PB, Bromfield EB, et al. (2004) Differential effects of antiepileptic drugs on sexual function and reproductive hormones in men with epilepsy: interim analysis of a comparison between lamotrigine and enzyme-inducing antiepileptic drugs. Epilepsia 45: 764-768.

15. Herzog AG, Drislane FW, Schomer DL, Pennell PB, Bromfield EB, et al. (2005) Differential effects of antiepileptic drugs on sexual function and hormones in men with epilepsy. Neurology 65: 1016-1020.

16. Brannon GE, Rolland PD (2000) Anorgasmia in a patient with bipolar disorder type 1 treated with gabapentin. J Clin Psychopharmacol 20: 379-381.

17. Rättyä J, Turkka J, Pakarinen AJ, Knip M, Kotila MA, et al. (2001) Reproductive effects of valproate, carbamazepine, and oxycarbamazepine in men with epilepsy. Neurology 56: 31-36.

18. Rosen RC, Riley A, Wagner G, Osterloh IH, Kirkpatrick J, et al. (1997) The international index of erectile function (IIEF): a multidimensional scale for assessment of erectile dysfunction. Urology 49: 822-830

19. Rosen RC, Cappelleri JC, Gendrano N 3rd (2002) The International Index of Erectile Function (IIEF): a state-of-the-science review. Int J Impot Res 14: 226 244

20. Reynolds CF 3rd, Frank E, Thase ME, Houck PR, Jennings JR, et al. (1988) Assessment of sexual function in depressed, impotent, and healthy men: facto analysis of a Brief Sexual Function Questionnaire for men. Psychiatry Res 24: 231-250.

21. Montouris G, Morris GL 3rd (2005) Reproductive and sexual dysfunction in men with epilepsy. Epilepsy Behav 7 Suppl 2: S7-14.

22. Hierons $R$, Saunders $M$ (1966) Impotence in patients with temporal-lobe lesions. Lancet 2: 761-763. 
Citation: Urso L, Zummo L, Gammino M, Fierro B, Pavone C, et al. (2014) Antiepileptic Drugs, Sexual Functions and Serum Hormonal Profile in Males with Epilepsy. Med Surg Urol 3: 130. doi:10.4172/2168-9857.1000130

Page 5 of 5

23. Kolárský A, Freund K, Machek J, Polák O (1967) Male sexual deviation. Association with early temporal lobe damage. Arch Gen Psychiatry 17: 735743

24. Stoffel-Wagner B, Bauer J, Flügel D, Brennemann W, Klingmüller D, et al. (1998) Serum sex hormones are altered in patients with chronic temporal lobe epilepsy receiving anticonvulsant medication. Epilepsia 39: 1164-1173.

25. Bauer J, Stoffel-Wagner B, Flügel D, Kluge M, Schramm J, et al. (2000) Serum androgens return to normal after temporal lobe epilepsy surgery in men. Neurology 55: 820-824

26. Kuba R, Pohanka M, Zákopcan J, Novotná I, Rektor I (2006) Sexual dysfunctions and blood hormonal profile in men with focal epilepsy. Epilepsia 47: 2135-2140.

27. Connell JM, Rapeport WG, Beastall GH, Brodie MJ (1984) Changes in circulating androgens during short term carbamazepine therapy. $\mathrm{Br} \mathrm{J}$ Clin Pharmacol 17: 347-351.

28. Luef GJ (2008) Epilepsy and sexuality. Seizure 17: 127-130.

29. Duncan S, Talbot A, Sheldrick R, Caswell H (2009) Erectile function, sexual desire, and psychological well-being in men with epilepsy. Epilepsy Behav 15: 351-357.
Citation: Urso L, Zummo L, Gammino M, Fierro B, Pavone C, et al. (2014) Antiepileptic Drugs, Sexual Functions and Serum Hormonal Profile in Males with Epilepsy. Med Surg Urol 3: 130. doi:10.4172/2168-9857.1000130
Submit your next manuscript and get advantages of OMICS Group submissions

Unique features:

- User friendly/feasible website-translation of your paper to 50 world's leading languages

Audio Version of published paper

Digital articles to share and explore

Special features:

350 Open Access Journals

30,000 editorial team

21 days rapid review process

Quality and quick editorial, review and publication processing

- Indexing at PubMed (partial), Scopus, EBSCO, Index Copernicus and Google Scholar etc

- Sharing Option: Social Networking Enabled

- Authors, Reviewers and Editors rewarded with online Scientific Credits

- Better discount for your subsequent articles

Submit your manuscript at: http://www.omicsonline.org/submission/ 